\title{
Does early supplementation of vitamin A show good efficacy on the prevention of bronchopulmonary dysplasia?
}

\author{
Jiangfeng $\mathrm{Wu}^{\wedge}$, Peiwen Wang, Weiqiang Bao, Jingwen Zhang, Yun Jin \\ Department of Ultrasound, The Affiliated Dongyang Hospital of Wenzhou Medical University, Dongyang, China \\ Correspondence to: Jiangfeng Wu. Department of Ultrasound, The Affiliated Dongyang Hospital of Wenzhou Medical University, No. 60 Wuning \\ West Road, Dongyang, 322100, China. Email: wjfhospital@163.com. \\ Comment on: Huang L, Zhu D, Pang G. The effects of early vitamin A supplementation on the prevention and treatment of bronchopulmonary \\ dysplasia in premature infants: a systematic review and meta-analysis. Transl Pediatr 2021;10:3218-29.
}

Submitted Dec 06, 2021. Accepted for publication Jan 30, 2022.

doi: $10.21037 /$ tp-21-575

View this article at: https://dx.doi.org/10.21037/tp-21-575

We read with great interest the recent published study by Huang and colleagues entitled "The effects of early vitamin A supplementation on the prevention and treatment of bronchopulmonary dysplasia (BPD) in premature infants: a systematic review and meta-analysis" (1). They found that early supplementation of vitamin A can prevent and treat BPD in premature infants. We appreciate Huang and colleagues for the valuable study, however, after a careful learning of the literature, we would like to pay attention to some important missing aspects in the study.

First, in the results section of the abstract, the outcome indicators such as 28-day oxygen uptake rate, 36-week survival rate, incidence of patent ductus arteriosus, days of mechanical ventilation, and 28-day ventilator use were not statistically significant between experimental group and control group because of $\mathrm{P}>0.05$. Therefore, the conclusion that early supplementation of vitamin A can prevent and treat BPD in premature infants might not be reliable.

Second, the effect size of the BPD incidence was odds ratio $(\mathrm{OR})$ revealed in figure 4 . In any case, the value of $\mathrm{OR}$ can never be negative, so the pooled OR of BPD incidence $(-0.71,95 \%$ CI: -0.34 to 0.00$)$ was calculated by mistake and should be further revised.

Finally, in figure 6, the meta-analysis on the 36-week survival rate was performed by using a random effect model. However, the enrolled articles were considered to be homogeneous because of $\mathrm{P}=0.51$ and $\mathrm{I}^{2}=0 \%$. We believe that the fixed effect model should be adopted actually.

\section{Acknowledgments}

Funding: None.

\section{Footnote}

Provenance and Peer Review: This article was a standard submission to the journal. The article has undergone external peer review.

Conflicts of Interest: All authors have completed the ICMJE uniform disclosure form (available at https://tp.amegroups. com/article/view/10.21037/tp-21-575/coif). The authors have no conflicts of interest to declare.

Ethical Statement: The authors are accountable for all aspects of the work in ensuring that questions related to the accuracy or integrity of any part of the work are appropriately investigated and resolved.

Open Access Statement: This is an Open Access article distributed in accordance with the Creative Commons Attribution-NonCommercial-NoDerivs 4.0 International License (CC BY-NC-ND 4.0), which permits the noncommercial replication and distribution of the article with the strict proviso that no changes or edits are made and the original work is properly cited (including links to both the formal publication through the relevant DOI and the license).

^ ORCID: 0000-0002-5036-799X. 
See: https://creativecommons.org/licenses/by-nc-nd/4.0/.

\section{References}

1. Huang L, Zhu D, Pang G. The effects of early vitamin

Cite this article as: $\mathrm{Wu} \mathrm{J}$, Wang $\mathrm{P}$, Bao W, Zhang J, Jin Y. Does early supplementation of vitamin A show good efficacy on the prevention of bronchopulmonary dysplasia? Transl Pediatr 2022;11(3):423-424. doi: 10.21037/tp-21-575
A supplementation on the prevention and treatment of bronchopulmonary dysplasia in premature infants: a systematic review and meta-analysis. Transl Pediatr 2021;10:3218-29. 